\title{
Correction to "Incretin Mimetics and DPP-IV Inhibitors: New Paradigms for the Treatment of Type 2 Diabetes"
}

The statement of competing interests was incomplete in the abovementioned article (Hinnen D, Nielsen LL, Waninger A, Kushner P. J Am Board Fam Med 2006;19(6):612-620). The JABFM editors asked the authors to disclose all real and potential conflicts of interest, and they provided the following information:

Deborah Hinnen currently serves on advisory boards and consults for companies including Eli Lilly, Aventis, Abbott, Roche, and Novartis. In the past, she served on boards or consulted for companies such as Novo Nordisk and Amylin. Currently, Ms. Hinnen is a speaker for APhA, American Association of Diabetes Educators, Eli Lilly, Amylin, Roche, NDEI, PESG, Aventis, and Pfizer. In the past, she was a speaker for various pharmaceutical and medical education companies including Johns Hopkins, VOX, Novo Nordisk, and Bio Centric.

Loretta L. Nielsen is an employee and stockholder of Amylin Pharmaceuticals, Inc.

Amy Waninger is an employee and stockholder of Eli Lilly and Company.

Pamela Kushner has served on advisory boards for Eli Lilly, Proctor and Gamble, Astra Zeneca, and Pfizer. She has performed research for Sanofi, Astra Zeneca, Novartis, and Proctor and Gamble. Dr. Kushner also served as a speaker for Pfizer, Eli Lilly, Proctor and Gamble, Astra Zeneca, Novartis, and GlaxoSmithKline. Stock ownership includes Pfizer, Eli Lilly, GlaxoSmithKline, and Wyeth. (doi: 10.3122/jabfm.2007.02.061000.) 